\title{
EL GÉNERO Flabellipecten EN EL NEÓGENO DE ANDALUCÍA OCCIDENTAL
}

\section{Joaquín CÁRDENAS CARRETERO}

Plaza de España 10, $1^{\circ}$ D. 41700 Dos Hermanas (Sevilla)

\begin{abstract}
Cárdenas Carretero, J. 2003. El género Flabellipecten en el Neógeno de Andalucía occidental. [The genus Flabellipecten in the Neogene of western Andalusia.] Revista Española de Paleontología, 18(1), 113-127. ISSN 0213-6937.
\end{abstract}

\begin{abstract}
ABSTRAC
Different species of the genus Flabellipecten from western Andalusia, (Huelva, Sevilla and Cadiz) have been revised confirming the existence of : F. solarium (Lamarck), $F$. fraterculus (Sowerby), $F$. burdigalensis (Lamarck), F. expansus (Sowerby), F. bosniasckii (De Stefani and Pantanelli) and F. flabelliformis (Sowerby). In spite of these species are quite common many of them have not been mentioned up to now.

Localities and lithologies where they have been found are mentioned for each species. They are all described and a short disscusion and some taphonomical data are given. Also a detailed recopilation of all outcrops aforementioned in Spain and other countries is included to stablish its well-known geostratigraphical distribution nowadays.

On the other hand, the species $F$. burdigalensis and $F$. expansus, mentioned species in lower and middle Miocene, have been frequently found in the late Miocene and perhaps early Pliocene of the area studied.
\end{abstract}

Keywords: Pectininae, Flabellipecten, Neogene, western Andalusia.

\section{RESUMEN}

Se hace una revisión de la presencia de las diferentes especies del género Flabellipecten en Andalucía occidental (provincias de Huelva, Sevilla y Cádiz) comprobando la existencia de las siguientes especies: $F$. solarium (Lamarck), F. fraterculus (Sowerby), F. burdigalensis (Lamarck), F. expansus (Sowerby), F. bosniasckii (De Stefani y Pantanelli) y F. flabelliformis (Brocchi), algunas de ellas bastante frecuentes y no citadas hasta ahora.

De cada especie se citan localidades y litologías donde han sido halladas. Se describen todas las especies, se hace una breve discusión y se dan algunos caracteres tafonómicos. También se hace una abundante recopilación de todas las citas en España y en otros países a fin de establecer su distribución geoestratigráfica conocida en la actualidad.

Respecto de $F$. expansus y $F$. burdigalensis, especies citadas en el Mioceno inferior y medio, se comprueba su frecuente presencia en el Mioceno final de la zona aquí estudiada.

Palabras clave: Pectininae, Flabellipecten, Neógeno, Andalucía occidental.

\section{INTRODUCCIÓN}

El conocimiento de la distribución, tanto espacial como temporal, de las especies de pectínidos, y en especial del género Flabellipecten, a lo largo del Neógeno en el sector occidental de la Cuenca del Guadalquivir es interesante ya que permite establecer datos muy valiosos para saber su dispersión paleobiogeográfica entre los dominios Atlántico y Mediterráneo.

En esta línea se encuentra el trabajo sobre los pectínidos en el Neógeno bético de Demarcq (1990), en el cual, aunque se menciona una localidad de la zona occidental (cita el yacimiento de El Rompido al que equivocadamente ubica en Cádiz cuando es de la provincia de Huelva), estudia sobre todo materiales y localidades del Levante español, Alicante y Murcia.

También en esta misma línea se encuentra el presente trabajo que, al ser del sector occidental de Andalucía (Fig. 1), complementa en parte el estudio de Demarcq. Este autor, entre los pectínidos que estudia, cita las siguientes especies del género Flabellipecten: $F$. cf. solarium (Lamarck), F. bosniasckii (De Stefani y Pantanelli), F. cf. nigromagnus (Sacco), F. incrassatus Partsch, F. fraterculus (Sowerby), F. flabelliformis (Brocchi), F. alesii (Philippi) y F. ugolini Deperet y Roman. De estas especies, $F$. alesii es la única que 


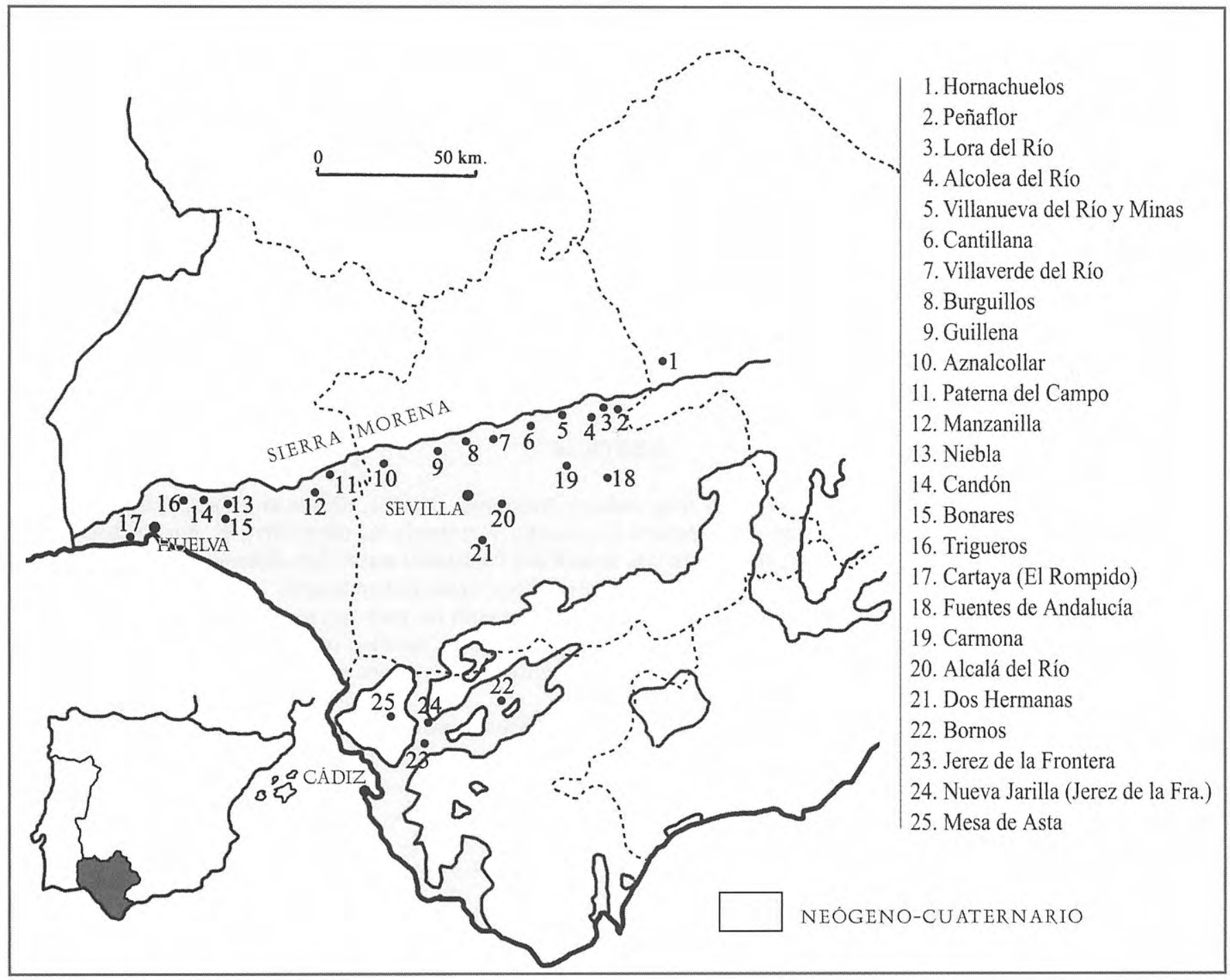

Figura 1. Mapa de Andalucía occidental mostrando las localidades citadas en este trabajo.

Map of the wertern Andalusia showing the localities mentioned in this work.

aparece en el levante español y que no ha sido localizada, hasta ahora, en la zona occidental andaluza. En cuanto a las demás especies nombradas por Demarcq, $F$. nigromagnus la cita en El Rompido (Huelva) y considera su clasificación dudosa; F. ugolinii, abundante en la zona que aquí se estudia, es considerada actualmente sinónima de Amussiopecten (Costellamussiopecten) koheni (Fuchs) (ver Cárdenas, 1998), y F. incrassatus es considerada sinónima de $F$. solarium.

Si a la lista anterior añadimos $F$. burdigalensis y $F$. expansus, especies estudiadas en este trabajo, tenemos una relación completa de las especies del género Flabellipecten identificadas, hasta la fecha, en el Neógeno de Andalucía y Levante peninsular.

Las especies del género Flabellipecten, como muchos otros taxones, tras habitar las cuencas centroeuropeas y Mediterráneo durante el Mioceno inferior y medio, se fueron replegando hacia el sur manteniendo allí su existencia en el Mioceno superior, Plioceno e incluso durante el Pleistoceno. En este sentido, Demarcq (1990) habla de santuario biológico en la zona de Alborán durante el Messiniense, que actuó como refugio de ambiente eurihalino en la crisis de salinidad del Mediterráneo, y desde aquí se realizó una posterior repoblación de especies, en este mar, al principio del Plioceno, una vez pasada dicha crisis, como consecuencia de nuevas comunicaciones con el Atlántico.

Se ha realizado una exhaustiva recopilación de las citas hechas para cada especie con el propósito de conocer su exacta distribución estratigráfica y geográfica, comprobando, por datos anteriores y los aportados en este trabajo, cómo los hábitats más recientes, antes de desaparecer de la zona, de las especies aquí estudiadas se localizan en el sur de la península Ibérica, norte de África y/o países de Oriente próximo. En la Figura 2 queda reflejada la distribución estratigráfica para las especies aquí estudiadas.

El género Flabellipecten desapareció totalmente del Mediterráneo y Atlántico a principio del Pleistoceno quedando en la actualidad relegado con pocas especies a diferentes zonas del Pacifico norte (Deperet y Roman, 1912). 


\begin{tabular}{|c|c|c|c|c|c|c|c|c|}
\hline \multirow{2}{*}{ ESPECIES } & \multicolumn{6}{|c|}{ MIOCENO } & \multicolumn{2}{|c|}{ PLIOCENO } \\
\hline & Aquitanien. & Burdigalien. & Langiense & Serravalien. & Tortoniense & Messinien. & Tabianiense & Plaseciense \\
\hline F. solarium & & $\cdots$ & & & & & & \\
\hline$F$. fraterculus & $\ldots \ldots \ldots \ldots \ldots$ & ………………… & $\ldots$ & 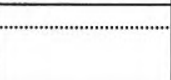 & & & 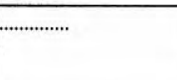 & \\
\hline F. burdigalensis & & & & & & & $?$ & \\
\hline F. expansus & & 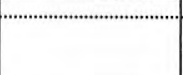 & 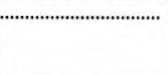 & & & & $?$ & \\
\hline$F$. flabelliformis & & & & & & & & $\ldots \ldots \ldots \ldots$ \\
\hline F. bosniaskii & & & & & & & & \\
\hline
\end{tabular}

Figura 2. Distribución estratigráfica de las especies de Flabellipecten durante el Neógeno.

.................. Distribución conocida hasta ahora.

Distribución en la zona de estudio según los datos aportados en este trabajo.

Stratigraphic distribution of the species of Flabellipecten during the Neogene.

.................. Well-known distribution up to now.

Distribution in the studied area based on the data offered in this work.

\section{MARCO GEOLÓGICO}

La zona estudiada comprende las provincias de Cádiz, Huelva y Sevilla (Fig.1). En este sector, los terrenos Neógenos abarcan la zona occidental de la Cuenca del Guadalquivir, cuencas menores intrabéticas o marginales (Jerez de la Frontera, Arcos de la Frontera-BornosVillamartín, Medina Sidonia-Vejer de la Frontera), franja litoral de Cádiz y algunos vestigios dispersos.

Tectónicamente, la Cuenca del Guadalquivir se formó como fosa marginal de antepaís durante la fase de plegamientos y cabalgamientos de la Cordillera Bética. (Martínez del Olmo et al., 1984; Portero García y Álvaro López, 1984). El borde norte, que actuó como margen pasivo, estuvo afectado por fallas y sufrió importantes movimientos de subsidencia. El margen sur-sureste fue un frente muy activo e inestable debido al avance de los frentes de cabalgamientos del orógeno hacia el centro de la cuenca. Al mismo tiempo se produjeron deslizamientos gravitacionales del margen sur que arrastraron materiales alóctonos de diferentes edades y que se intercalaron con los sedimentos autóctonos. Estos materiales forman el frente olistostrómico.

Este avance irregular dio lugar a depresiones que iban formándose entre las nacientes elevaciones montañosas, las cuales quedaban ocupadas por cuencas marinas marginales y conectadas con la antefosa.

Como consecuencia del máximo apilamiento de materiales de la Cordillera Bética sobre la zona, se produjo un hundimiento del zócalo Paleozoico que provocó la máxima transgresión del mar en la antefosa durante el Tortoniense superior. Durante el Plioceno y
Pleistoceno también aparecen nuevas pulsaciones tectónicas con fases distensivas y compresivas las cuales dieron lugar a nuevas transgresiones y regresiones de menor intensidad que afectaron sobre todo a la cuenca de Jerez de la Frontera y a la costa gaditana (Viguier, 1974; Ruiz Reig et al., 1994).

\section{ESTRATIGRAFÍA}

Los estratos se presentan horizontales o con ligeros buzamientos desde la zona centro a norte de la cuenca. En la zona sur, la secuencia estratigráfica se complica como consecuencia del avance del frente activo, acción de los olistostromas o por movimientos diapíricos y extrusión de margas del Triásico subyacente, durante la fase de compresión Plio-Cuaternaria.

De entre todas las unidades estratigráficas neógenas de la zona de estudio, solo se analizarán aquellas donde se localicen las especies fósiles sujetos de este trabajo.

Las diferentes formaciones y sus edades, localidades y litologías donde se han hallado especies de Flabellipecten quedan recogidas en la Fig. 3.

Formación Niebla: La constituyen una serie de materiales que se depositaron, discordantes, sobre el zócalo Paleozoico durante la transgresión en el Tortoniense superior. Estos materiales se definieron, en Huelva, como Formación Calcarenitas de Niebla ( Civis et al., 1987), la cual es muy variable debido a la presencia de facies diferentes. Por esta razón, Baceta y Pendón (1999) la redefinieron como Formación Niebla, en la que diferencian cinco asociaciones 


\begin{tabular}{|c|c|c|c|c|c|c|c|c|}
\hline \multirow[b]{2}{*}{ Localidades } & \multicolumn{6}{|c|}{ Taxones } & \multirow[b]{2}{*}{ Litología } & \multirow[b]{2}{*}{ Formaciones y Edades } \\
\hline & 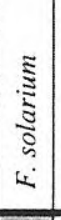 & 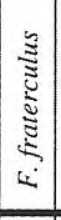 & 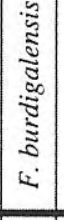 & 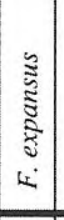 & 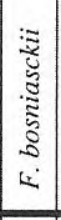 & 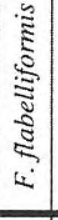 & & \\
\hline Hornachuelos & & & & & & & Caliza arenosa compacta & \multirow{14}{*}{ 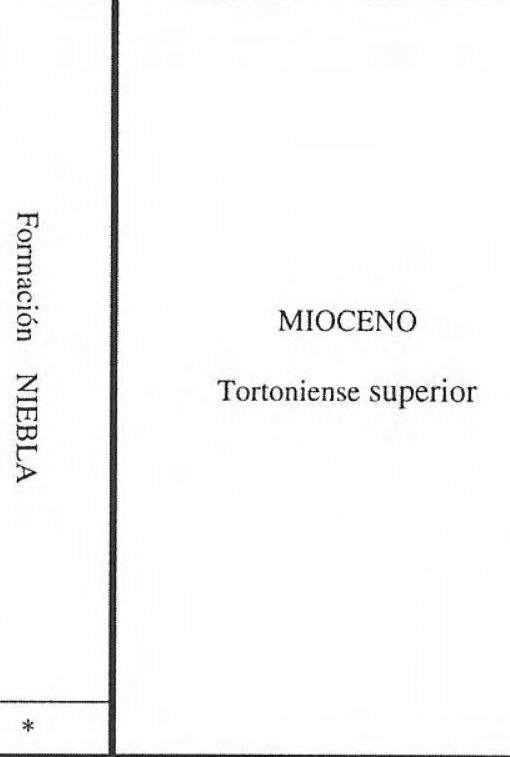 } \\
\hline Peñaflor & & & & & & & Caliza arenosa compacta & \\
\hline Lora del Río & & & & & & & Caliza arenosa compacta & \\
\hline Alcolea del Río & & & & & & & Arenas, gravas, calcarenitas & \\
\hline Villanueva del Río y Minas & & & & & & & $\begin{array}{l}\text { Arenas limosas, } \\
\text { conglomerados }\end{array}$ & \\
\hline Villaverde del Río & & & & & & & Calcarenitas, arenas limosas & \\
\hline Paterna del Campo & & & & & & & Calcarenitas & \\
\hline Niebla & & & & & & & Calcarenitas & \\
\hline Candón & & & & & & & Calcarenitas & \\
\hline Burguillos & & 8 & & & & & Arenas limosas & \\
\hline Guillena & & & & & & & Arenas limosas & \\
\hline Aznalcollar & & & & & & & Calcarenitas & \\
\hline Cantillana & & & & & & & Arenas limosas & \\
\hline Bornos* & & ? & & & & & Calcarenitas & \\
\hline Manzanilla & & & & & & & Arcillas margo-arenosas & \multirow{3}{*}{$\begin{array}{c}\text { Contacto entre Fm. ARCILLAS DE } \\
\text { GIBRALEÓN } \\
\text { y Fm. ARENAS DE HUELVA } \\
\text { Messiniense- PLIOCENO INFERIOR }\end{array}$} \\
\hline Bonares & & & & & & & Arcillas margo-arenosas & \\
\hline Trigueros & & & ? & & & & Arenas limosas & \\
\hline Alcalá de Guadaira & & & & & & & Calcarenitas & \multirow{3}{*}{$\begin{array}{l}\text { Formación GUADAIRA } \\
\text { Messiniense superior }\end{array}$} \\
\hline Carmona & & & & & & & Calcarenitas & \\
\hline Dos Hermanas & & & & & & & Calcarenitas & \\
\hline Fuentes de Andalucía & & & & & & & Arenas, areniscas & Messiniense \\
\hline Cartaya (El Rompido) & & & & & & & Arenas limosas & \multirow{4}{*}{ PLIOCENO INFERIOR y MEDIO } \\
\hline Jerez de la Frontera & & & & & & & Arenas & \\
\hline Nueva Jarilla (Jerez de la F.) & & & & & & & Arenas, calcarenitas & \\
\hline Mesa de Asta & & & & & & & Arenas, calcirruditas & \\
\hline
\end{tabular}

Figura 3. Localidades, litologías y edades donde han sido halladas las diferentes especies de Flabellipecten. (*) Los materiales de esta localidad no pertenecen a la Formación Niebla. Localities, lithologies and ages where of the different Flabellipecten species studied in this paper. (*)The rocks of this locality don't belong to the Niebla Formation.

de facies: a) de conglomerados, arenas y areniscas fluviales; b) barras deltáicas; c) arenas y limos ricos en Heterostegina sp.; d) calcarenitas arenosas y conglomerados de playas; e) calcarenitas bioclásticas (a veces calcirruditas) de plataforma somera. La formación concluye con unas margas arenosas ricas en glauconita (Civis et al.,1987). Estas facies se presentan unas veces superpuestas y otras veces conectadas lateralmente en función del paleorrelieve y otras condiciones paleoambientales.

Formación Arcillas de Gibraleón: El último tramo de la formación anterior pasa progresivamente a la Formación
Arcillas de Gibraleón (Civis et al.,1987), la cual es equivalente a la Formación Écija (Verdenius, 1970) definida en Sevilla y Córdoba. Se denominan informalmente como margas azules. Son arcillas, más o menos margosas, grisesazuladas, mientras que hacia el techo y a los márgenes de la formación presentan tonalidades entre verdes, amarillentas o marrones y, en ocasiones, una textura más arenosa. Se le atribuye una edad Tortoniense superior-MessiniensePlioceno inferior (Civis et al., 1987).

Formación Arenas de Huelva: En concordancia con los materiales anteriores se superponen unas arenas finas 
marrones amarillentas y algo limosas, definidas como Arenas de Huelva (Civis et al., 1987) de edad Plioceno inferior. Se inicia esta unidad estratigráfica con un tramo rico en glauconita, que es observable en el muro de casi toda la formación. En su seno se encuentran varios niveles muy fosilíferos.

Formación Guadaira: Sobre las Arcillas de Gibraleón (margas azules), se encuentran unas arenas, que localmente se recargaron de materiales siliciclásticos más gruesos y con una abundante cantidad de bioclastos calcáreos que dieron lugar a las calcarenitas propias de esta formación. Geográficamente se encuentran en una franja que se extiende de NE a SO en el centro de la provincia de Sevilla, entre las localidades de Carmona y Dos Hermanas. Estos materiales se han designado con diferentes nombres: Formación Guadaira (Verdenius, 1970); "Caliza tosca" de Carmona (Perconig y Granados, 1973); Formación del Alcor (Viguier, 1974), y popularmente son conocidas como "Albero". La datación de estos materiales ha variado en las últimas décadas entre Tortoniense superior y Plioceno inferior. Últimamente (Sierro et al.,1990 y 1996) consideran Messiniense superior las calcarenitas, en Carmona.

Arenas, areniscas y calcarenitas: Excepto las arenas y areniscas de Fuentes de Andalucía, de edad Messiniense (Crespo et al., 1977), los materiales a los que se hace referencia se encuentran dispersos en grandes manchas en zonas cercanas a Jerez de la Frontera. Pertenecen al Plioceno inferior y medio (Ruiz Reig et al., 1994).

\section{PALEONTOLOGÍA SISTEMÁTICA}

Todos los ejemplares figurados y medidos en este trabajo han quedado depositados en el Museo Geológico de la Universidad de Sevilla.

En las tablas de medidas, los ejemplares señalados por /a y /b corresponden a las dos valvas de un mismo ejemplar articulado. Cuando por deterioro de la concha la medida es aproximada, se acompaña ésta de asterisco y si es imposible tomarla, aparece un guión en el casillero correspondiente. Las descripciones se han realizado teniendo en cuenta las características observadas en todo el material estudiado para cada especie.

Superfamilia Pectinoidea Rafinesque, 1815 Familia Pectinidae Rafinesque, 1815 Género Flabellipecten Sacco, 1897

\section{Flabellipecten solarium (Lamarck, 1819) Fig. $4 \mathrm{~A}$}

1908 Flabellipecten incrassatus Partsch; Ugolini, 194, lám. 23, figs. 3-4.

1910 Flabellipecten incrassatus Partsch; Depert y Roman, 122, lám. 14, figs. 1-2.

1939 Chlamys solarium (Lamarck); Roger, 13, lám. 16, figs. 9-10.

\begin{tabular}{lcccc}
\hline Ejemplar & valva & d.a.p. & d.u.p. & ángulo apical \\
\hline MGUS - 2073 & V.D. & 175 & 158 & $133^{\circ}$ \\
MGUS - 2074/a & V.D. & 141 & 122 & $133^{\circ}$ \\
MGUS - 2074/b & V.I. & 132 & 119 & $145^{\circ}$ \\
MGUS - 2075 & V.D. & 184 & 156 & $137^{\circ}$ \\
MGUS - 2076 & V.I. & 185 & 164 & $145^{\circ}$ \\
MGUS - 2077 & V.D. & 198 & 177 & $140^{\circ}$ \\
\hline
\end{tabular}

Tabla 1. Medidas de algunos ejemplares de F. solarium. Measurements in some specimens of $\mathrm{F}$. solarium.

1951 Chlamys solarium (Lamarck); Veiga Ferreira, 13, lám. 10, figs. 44-47.

1960 Flabellipecten solarium (Lamarck); CsepreghyMezneries, 15, lám. 7, figs. 3-7 y lám 8, figs. 1-3.

1965 Oopecten (s.s.) solarium (Lamarck); Glibert y Van de Poel, 17.

1972 Flabellipecten solarium (Lamarck); Comaschi Caria, 26, lám. 5, figs. 1, 4, 5.

1987 Flabellipecten solarium (Lamarck); Ben Moussa et al., 120.

1987 Flabellipecten solarium (Lamarck); Freneix et al., 30, lám. 6, fig. 1 .

Material y localidades: El material estudiado procede de las siguientes localidades: Hornachuelo, Peñaflor, Lora del Río, Alcolea del Río, Villanueva del Río y Minas (MGUS2075, MGUS-2077), Villaverde del Río, Aznalcollar, Paterna del Campo (MGUS-2074/a y /b), Niebla, Candón y Bornos (MGUS-2073, MGUS-2076). Se han estudiado 14 valvas derechas, 11 valvas izquierdas, 4 ejemplares articulados y numerosos fragmentos. Se han seleccionados los seis ejemplares en mejor estado de conservación (no todos totalmente completos) cuyas siglas y medidas quedan reflejadas en la Tabla I.

\section{Descripción}

Concha de mediano a gran tamaño, de forma extendida lateralmente siendo algo más larga que alta, diámetro anteroposterior (d.a.p.) mayor que diámetro umbo-paleal (d.u.p.).

La valva derecha es convexa, poco profunda, con umbo suave que no sobrepasa el margen cardinal. Dicho margen, ligeramente escamoso, no forma una línea recta debido a una depresión de éste en el ápice y al ligero levantamiento, y algo brusco, de la orejeta anterior. El ángulo apical varía entre $132^{\circ}$ y $140^{\circ}$. La valva se extiende lateralmente y se aplana en los márgenes. Posee 15 costillas principales de sección redondeada en el umbo, que se ensanchan y aplanan posteriormente, llegando como suaves ondulaciones al margen paleal. Siempre son más anchas que los intervalos. Los márgenes, más o menos planos, son recorridos por dos costulaciones muy difuminadas. Las orejas son grandes en sentido longitudinal, bajas y subiguales; la anterior, a veces, más corta y alta que la posterior, con seno bisal bien marcado. Por su margen superior, ambas orejas crecen inclinándose hacia el exterior de la concha creándose así, en su cara interna, un plano inclinado el cual presenta unas 
finas y apretadas líneas de crecimiento perpendiculares al eje cardinal. La superficie de la valva posee abundantes líneas de crecimiento que se aprecian como débiles lamelas en los intervalos de los ejemplares jóvenes y a lo largo del borde paleal en los ejemplares adultos. En su cara interna, cada intervalo correspondiente a la decoración externa, queda muy marcado, sobre todo cerca del borde paleal, por dos aristas agudas que se acercan entre sí levemente y se reducen hasta desaparecer a unos milímetros del borde de la valva.

La valva izquierda, que es suavemente convexa con el ápice no deprimido, tiende a aplanarse hacia el borde paleal e incluso a curvarse levemente hacia fuera en los ejemplares de gran tamaño. Su ángulo apical es más abierto que en la valva derecha, variando entre $140^{\circ}$ y $145^{\circ}$. Su ornamentación la forman 13 o14 costillas principales de sección redondeada en el centro de la valva, que se aplanan y ensanchan al acercarse al margen paleal, donde son algo más anchas que los intervalos. Ambos flancos, el posterior algo más levantado, son recorridos por cuatro o más costulaciones muy finas. Toda la valva está ornamentada con lamelas de crecimiento apretadas que se hacen más patentes en los intervalos. Tanto sobre las costillas principales como en los intervalos se insinúan unas costulaciones longitudinales que sólo son apreciables en algunos ejemplares. Orejas iguales, bajas y largas, con 4 a 6 líneas radiales. Margen cardinal recto. Internamente, esta valva posee la misma decoración que la valva derecha.

\section{Discusión}

Los ejemplares estudiados poseen un tamaño comprendido entre las tallas de los ejemplares italianos, cuyas medidas varían entre $85,7 \mathrm{~mm}$ y $110 \mathrm{~mm}$ de d.u.p. en valvas izquierdas (Comaschi Caria, 1972), y un ejemplar marroquí de d.u.p. 180 mm (Ben Moussa, 1994). En cuanto a las demás características, no difieren de los ejemplares descritos por otros autores (Tabla 1).

\section{Observaciones tafonómicas}

Esta especie hubo de ser frecuente en las distintas facies litorales de la zona estudiada durante el Tortoniense superior. Se encuentran ejemplares en conglomerados deltaicos (cercanos a un banco de grandes Crassostraea gryphoides), arenas gruesas y calcarenitas (Fig 2). Demarcq (1979) comenta que esta especie, al igual que otros grandes pectínidos, solía habitar en plataformas someras con abundantes bioclastos, así como en lugares arenosos. Aquí también aparecen en arenas limosas, a veces, ejemplares articulados acompañados de abundantes Heterostegina sp.

La fauna acompañante más caracteristica está formada por: Gigantopecten albinus (Von Teppner), G. latissima latissima (Brocchi), G. latissima nodosiformis (De Serre), Chlamys seniensis (Lamarck), C. pusio (Linné),
Clypeaster portentosus Desmoulins, C. franchii (Checchia-Rispoli), Clypeaster sp., etc.

\section{Distribución}

Esta especie es frecuente en el Mioceno, extendiéndose desde el Burdigaliense hasta el Messiniense.

En la zona atlántica, se cita desde el Burdigaliense al Tortoniense en Francia, cuenca del Loira y Aquitania, y en Portugal en la zona de Lisboa (cuenca del Tajo) y en el "Helvetiense" del Algarve. En Europa central (Paratetis) se ha citado en el Mioceno medio de las cuencas de Viena, Hungría, Polonia y Alemania. En la zona mediterránea se encuentra desde el Burdigaliense al Messiniense de Francia, Valle del Ródano y Córcega; Italia, Alpes, Valle del Po y Cerdeña; Siria; Creta; Argelia, Marruecos y España (Veiga Ferreira, 1951; Csepreghy-Meznerics, 1960; Comaschi Caria, 1972)

En España se conoce en diversas localidades de Barcelona y Tarragona (Porta, 1969). También en Murcia, Sierra Carrascoy (Ben Moussa et al., 1987). En Enguera, Valencia, fue citado como $F$. cf. incrassatus (Darder, 1945). Demarcq (1990) la cita, sin especificar localidades, en el "Neógeno Bético" junto con F. incrassatus. Este autor las considera especies diferentes cuando la mayoría de los investigadores actuales consideran $F$. incrassatus como sinónimo de $F$. solarium.

\section{Flabellipecten fraterculus (Sowerby, 1841)} Fig. 4 B

1897 Flabellipecten cf. leythajanus (Partsch); Sacco, 5, lám.17, fig. 12.

1908 Flabellipecten vindascinus Ugolini, 197, lám.24, figs. 1-2.

1908 Flabellipecten grecoi Ugolini, 199, lám.24, figs. 4-5.

1910 Flabellipecten fraterculus (Sowerby); Depéret y Roman, 127, lám. 16, figs. 1-3.

1914 Pecten (Flabellipecten) vasatensis Cossman y Peirot, 287, lám. 14, figs. 1-4.

1939 Flabellipecten fraterculus (Sowerby); Roger, 249.

1951 Flabellipecten fraterculus (Sowerby); Veiga Ferreira, 10, lám. 4, figs. 9-14.

1951 Flabellipecten fraterculus avaticus Veiga Ferreira, 11, lám. 5, fig. 17.

1971 Flabellipecten fraterculus (Sowerby); Bauza Rullan, 421.

1972 Flabellipecten fraterculus (Sowerby); Comaschi Caria, 28, lám.5, figs. 2- 3; lám. 6, figs. 1-3.

1987 Flabellipecten fraterculus (Sowerby); Freneix et al., 28, lám. 5, figs. 1a-1b.

1987 Flabellipecten fraterculus (Sowerby); Ben Moussa et al., 121.

Figura 4. A. Flabellipecten solarium (Lamarck), MGUS-2075, x 0,47, valva derecha. Right valve. B. Flabellipecten fraterculus (Sowerby), MGUS-2078, x 1, valva derecha. Right valve. C. Flabellipecten bosniasckii (De Stefani y Pantanelli), MGUS-2096/a, x 0,74, valva derecha. Right valve. D. Flabellipecten burdigalensis (Lamarck), MGUS2084, x 0,58, valva derecha. Right valve. E. Flabellipecten expansus (Sowerby), MGUS-2091, x 0,7, valva izquierda. Left valve. F. Flabellipecten expansus, (Sowerby), MGUS-2088, x 0,78, valva derecha. Right valve. 


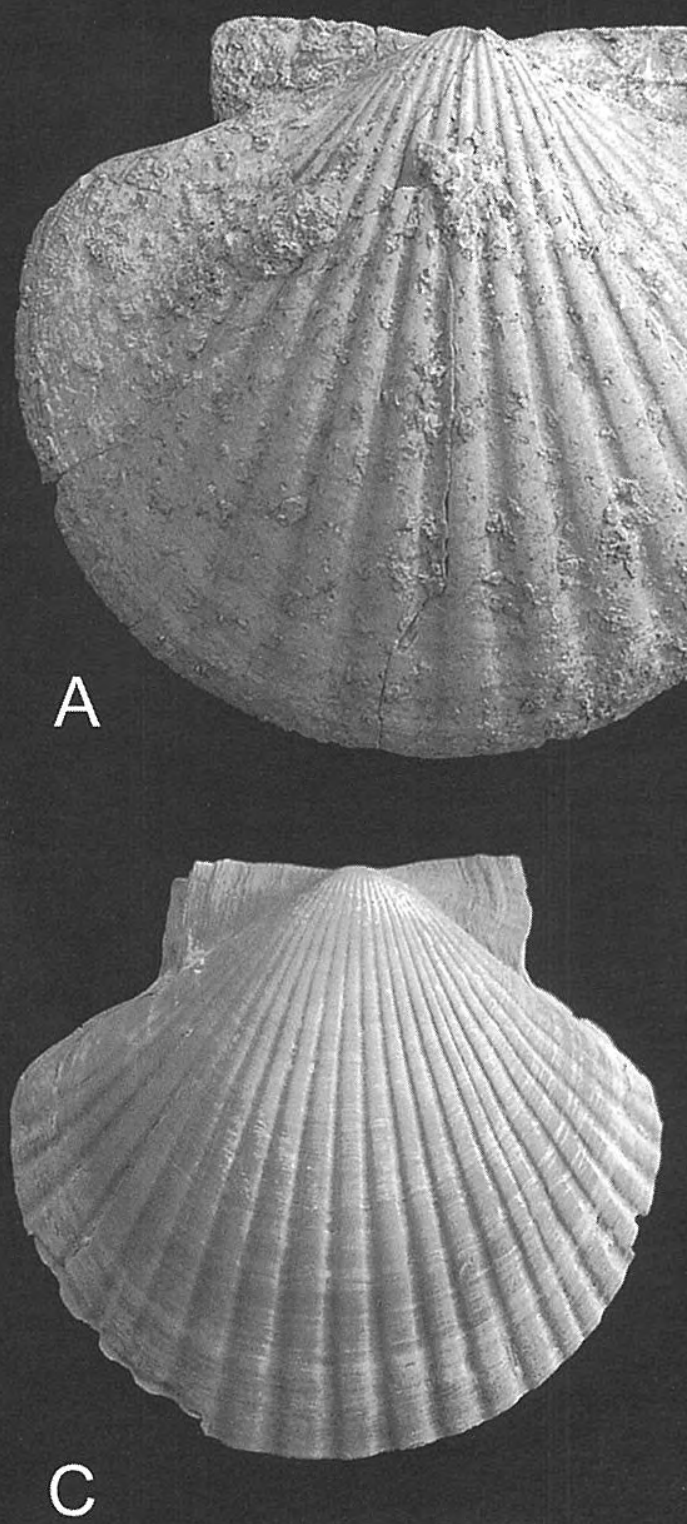

B
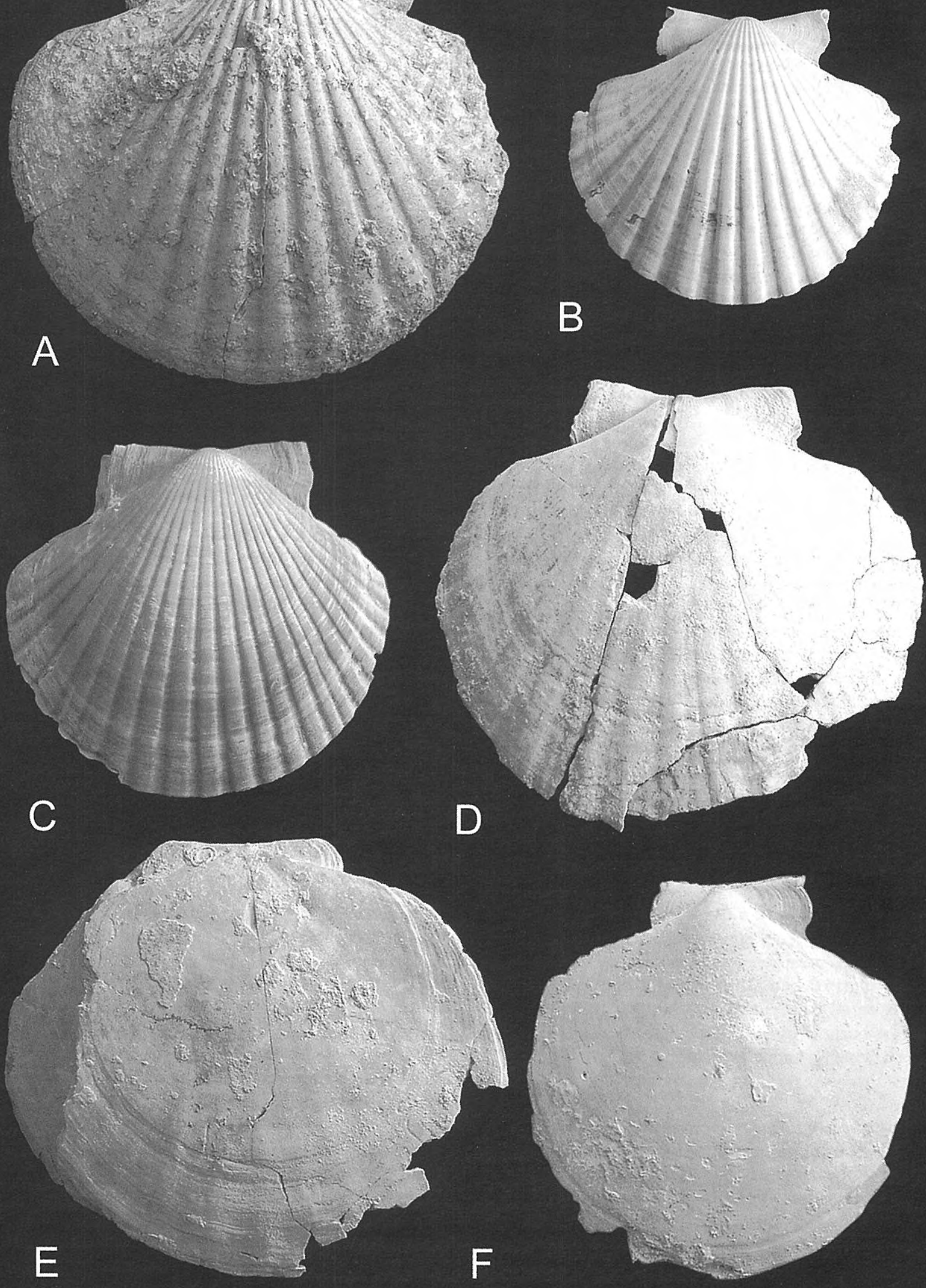
Material y localidades: El material procede de las localidades Alcolea del Río, Villanueva del Río y Minas (MGUS-2078, MGUS-2079), Villaverde del Río, Paterna del Campo (MGUS-2081/a y /b), Burguillos y Cantillana (MGUS-2080/a y /b, MGUS-2082). Se han estudiado 16 valvas derechas, 8 valvas izquierdas, 3 ejemplares articulados y numerosos fragmentos. Se han seleccionado 7 ejemplares en buen estado de conservación cuyas medidas, en milímetros, y siglas quedan reflejadas en la Tabla 2.

\section{Descripción}

Conchas de pequeño a mediano tamaño. Forma extendida lateralmente, siendo algo más larga que alta.

La valva derecha convexa, poco profunda, con umbo acusado, alto y que sobrepasa levemente la línea cardinal, la cual forma un ángulo muy abierto. El ángulo apical oscila entre $125^{\circ}$ y $130^{\circ}$. En los ejemplares muy jóvenes, el ángulo apical suele ser menor, bajando hasta $117^{\circ}$. La valva se extiende y aplana lateralmente. Posee 14 o 15 costillas principales y 1 o 2 costillas más débiles a cada lado. Todas son redondeadas en el umbo y se ensanchan y aplanan, tomando forma subcuadrada, hacia el borde paleal. Los intervalos son de fondo plano y algo más estrechos que las costillas. En los márgenes existen de dos a tres costillas más finas y débiles que las principales. Orejas medianas, subiguales, siendo la anterior algo más elevada que la posterior respecto del borde cardinal. Sus límites laterales son redondeados y ambos poseen un seno en la parte superior que les da forma de eses (la posterior invertida), cuyas asas superiores son pequeñas y las forma una vuelta en rodillo que da el margen superior. La anterior presenta en su base un marcado seno bisal. La superficie externa no presenta lamelas. En algunos ejemplares aparecen, únicamente dibujadas, líneas concéntricas de crecimiento. La unión entre el margen lateral del disco y la oreja posterior está excavado creando un surco muy marcado entre ambos.

La valva izquierda es ligeramente convexa respecto del d.u.p. y plana respecto del d.a.p., este último algo mayor que el anterior. El ápice está deprimido y los márgenes algo levantados. El ángulo apical varía entre $130^{\circ}$ y $142^{\circ}$. En ejemplares jóvenes puede bajar a $122^{\circ}$. Su ornamentación consiste en 13 costillas principales, redondeadas y algo más estrechas que los intervalos. En los laterales se aprecian $3 \mathrm{o}$ 4 estrías radiales. Toda la valva está cubierta de líneas concéntricas de crecimiento apretadas. Se aprecian mejor en los intervalos, pero persisten sobre las costillas e incluso en las orejas. En algunos ejemplares pueden llegar a ser débiles lamelas. Las orejas son iguales, con borde cardinal recto y algo curvadas hacia el exterior, estándolo más la anterior, a la vez que su dentelón auricular es más prominente.

\section{Discusión}

Atendiendo al número y características de las costillas, los ejemplares estudiados corresponden a la subespecie $F$. fraterculus fraterculus, taxón que reemplazó a la subespecie $F$. fraterculus avaticus Combaluzier del Mioceno inferior y medio. Esta última subespecie se diferencia de la primera por su número de costillas, que es menor, y poque éstas son menos pronunciadas y menos redondeadas.

\begin{tabular}{lcccc}
\hline Ejemplar & valva & d.a.p. & d.u.p. & ángulo apical \\
\hline MGUS - 2078 & V.D. & 64 & 53 & $128^{\circ}$ \\
MGUS - 2079 & V.D. & 32 & 30 & $117^{\circ}$ \\
MGUS - 2080/a & V.D. & 56 & 49 & $123^{\circ}$ \\
MGUS - 2080/b & V.I. & 53 & 48 & $131^{\circ}$ \\
MGUS - 2081/a & V.D. & 83 & 69 & $128^{\circ}$ \\
MGUS - 2081/b & V.I. & 76 & 68 & $142^{\circ}$ \\
MGUS - 2082 & V.I. & 60 & 54 & $140^{\circ}$ \\
\hline
\end{tabular}

Tabla 2. Medidas de algunos ejemplares de $F$. fraterculus. Measurements in some specimens of $\mathrm{F}$. fraterculus.

Los ejemplares estudiados se encuentran en todas las fases de crecimiento (Tabla 2). Los de mayor tamaño son comparables e incluso mayores que las medidas dadas por Comaschi Caria (1972) para unas valvas derechas cuyos d.u.p. varían entre $46,6 \mathrm{~mm}$ y $63,6 \mathrm{~mm}$. En cuanto al número de costillas (14 a15) difiere de las 16 costillas dadas por otros autores (Depèret y Roman, 1910; Freneix et al., 1987). Esto se puede explicar por la subjetividad al entender cuales son costillas principales o secundarias o porque algunas de estas últimas alcancen un desarrollo equiparable a las principales.

\section{Observaciones tafonómicas}

Esta especie, aunque aparece acompañando a $F$. solarium en las facies calcarenitosas, es más frecuente en arenas y arenas limosas (Fig. 3) donde aparecen ejemplares bien conservados, sin señales de arrastres, y a veces articulados. Ben Moussa (1994) la cita, también, en arenas y margas arenosas en diferentes puntos del norte de África.

Entre la fauna de pectínidos que acompaña a esta especie destacamos: F. burdigalensis (Lamarck), Amusium cristatum (Bronn), Pecten revolutus Michelotti, junto con las especies citadas que acompañan a $F$. solarium.

\section{Distribución}

Esta especie ha sido citada en todos los pisos del Mioceno, desde el Aquitaniense al Messiniense. También se cita en el Plioceno de algunas localidades de Marruecos y Siria (Freneix et al., 1987).

En la vertiente atlántica, se conoce desde el Burdigaliense al Tortoniense en Portugal: zona de Lisboa, Valle del Tajo, Setúbal y en el Algarve (Veiga Ferreira, 1951, 1954, 1961). En la zona mediterránea, se extiende desde el Aquitaniense hasta el Plioceno por numerosas localidades del sur y sudeste de España, Francia, Italia, Malta, Creta, Hungría, Siria, Libia, Argelia y Marruecos (Roger, 1939; Comaschi Caria, 1972; Freneix et al., 1987; Ben Moussa,1994).

En España, en el Burdigaliense de Altafalla y en el Tortoniese de Montjuich, ambas en Barcelona, además de otras localidades de Barcelona y Tarragona (Porta, 1969). En el Tortoniense de Picasent y Torrente, en Valencia (Acuña, 1978). Lorca, en Murcia (Roger, 1939). En el Messiniense 
de la zona de Murcia y Alicante, sin especificar localidades concretas, recolectadas por G. Demarcq. Y en la zona de Melilla (Ben Moussa et al., 1987).

\section{Flabellipecten burdigalensis (Lamarck, 1806)} Fig. $4 \mathrm{D}$

1897 Amussiopecten burdigalensis (Lamarck); Sacco, 53, lám. 15, figs. 1 a 7.

1907 Amussiopecten burdigalensis (Lamarck); Ugolini, 235.

1912 Flabellipecten burdigalensis (Lamarck); Depéret y Roman, 148, lám. 21, figs. 1, 1a, 2, 2a; lám. 23, figs. 1, 1a, 2, 3 .

1914 Flabellipecten burdigalensis (Lamarck); Cossman y Peirot, 290, lám.14, figs. 18-21.

1941 Flabellipecten cerulli Serra, 84, lám. 10, figs. 5 a 7.

1954 Flabellipecten burdigalensis (Lamarck); Veiga Ferreira, 20, lám. 1, figs. 3 y 4.

1960 Flabellipecten burdigalensis (Lamarck); CsepreghyMeznerics, 16, lám. 9, figs. 1, 2; lám. 10, figs. 1, 2; lám. 11, figs. 1 a 4 .

1972 Flabellipecten burdigalensis (Lamarck); Comaschi Caria, 30, lám. 7, figs. 1, 2.

Material y localidades: El material estudiado procede de Villanueva del Río y Minas, Burguillos (MGUS-2086, MGUS-2087), Guillena (MGUS-2084), Aznalcollar, Cantillana, Alcalá de Guadaira (MGUS-2083), Manzanilla (MGUS-2085) y Bonares. Se han estudiado un total de 29 valvas. De ellas solamente 2 valvas derechas y 10 valvas izquierdas de tamaño mediano están completas; las demás se encuentran algo o muy deterioradas. De entre ellas se han elegido cinco ejemplares cuyas siglas y medidas están representadas en la Tabla 3 .

\section{Descripción}

Concha de tamaño mediano a grande, equilateral, suborbicular y comprimida.

Valva derecha convexa, poco profunda, con umbo suavemente curvado que no sobrepasa la línea cardinal, la cual forma una uve muy abierta de brazos desiguales, siendo el anterior más largo y elevado. El ángulo apical puede alcanzar, en los ejemplares adultos, entre $130^{\circ}$ y $135^{\circ}$. La ornamentación, en la cara exterior, la constituyen 12 costillas principales, muy poco marcadas, planas y de mayor anchura que los intervalos. En algunos ejemplares, las costillas sólo se aprecian como unas suaves ondulaciones algo más marcadas hacia el borde paleal. En los márgenes laterales, casi lisos, se aprecian de 3 a 4 costillas aún más tenues que las principales. Como ornamentación secundaria presenta apretadas líneas de crecimiento bien visibles en el borde paleal. En el interior de esta valva, se observan listones finos emparejados que corresponden a los márgenes de los espacios intercostales de la cara exterior. Se encuentran en número de 16 a 18 pares (frecuentemente acompaña a cada lado un listón desparejado). Estas parejas son más prominentes en el borde paleal y desaparecen hacia el centro de la concha. Orejas grandes y desiguales. La

\begin{tabular}{lllll}
\hline Ejemplar & valva & d.a.p. & d.u.p. & ángulo apical \\
\hline MGUS - 2083 & V.D. & 59 & 53 & $135^{\circ}$ \\
MGUS - 2084 & V.D. & 146 & $128^{*}$ & $132^{\circ}$ \\
MGUS - 2085 & V.I. & 49 & 47 & $133^{\circ}$ \\
MGUS - 2086 & V.D. & - & 105 & $133^{\circ}$ \\
MGUS - 2087 & V.I. & 52 & 49 & $133^{\circ}$ \\
\hline
\end{tabular}

Tabla 3. Medidas de algunos ejemplares de F. burdigalensis. Measurements in some specimens of $\mathrm{F}$. burdigalensis.

anterior es algo mayor y con un marcado seno bisal en su base. El margen de la posterior, en el contacto con el margen del disco, está excavado formando un canal muy pronunciado.

La valva izquierda es suavemente convexa, con margen cardinal recto y ángulo apical mayor que en la valva derecha de los grandes ejemplares. Su ornamentación la forman 13 costillas que nacen finas y angulosas y antes de llegar al centro de la concha se ensanchan y aplanan siendo de mayor anchura que los intervalos. En otros ejemplares, dichas costillas solo se aprecian como dibujadas y con un suave relieve perceptible únicamente al tacto. Toda la valva presenta líneas de crecimiento abundantes y apretadas. El interior de esta valva presenta las mismas características que el de la valva derecha. Las orejas, desiguales, tienen el margen lateral redondeado y su ornamentación secundaria consiste en líneas de crecimiento.

\section{Discusión}

La especie $F$. burdigalensis presenta, en su cara externa, una variabilidad en el resalte de las costillas que va desde un relieve neto a una superficie casi lisa. Sowerby denominó a la variedad totalmente lisa Pecten expansus (Depéret y Roman, 1912).

Este carácter polimórfico también se constata en los ejemplares aquí estudiados. En Burguillos aparecen ejemplares completos y frecuentes fragmentos donde las costillas son muy poco prominentes, destacando algo más cuando éstas se acercan al borde paleal, donde se aprecian como una suave ondulación. En otros lugares, Manzanilla, Bonares y Alcalá de Guadaira, los ejemplares presentan unas costillas con un relieve bien acusado.

En cuanto al tamaño (Tabla 3), los ejemplares estudiados son medianos en su mayoría salvo dos valvas y fragmentos que corresponden a ejemplares de gran tamaño. Uno de ellos (Fig. 4D), fragmentado y reconstruido, tiene las mismas medidas que el representado por Depéret y Roman en 1912 (Lám. 23, fig. 1), conservado en el museo de Turín.

Esta especie ha sido ampliamente citada a lo largo de todo el Mioceno sin llegar al Plioceno. Sin embargo, los ejemplares aquí estudiados se encuentran en materiales del Tortoniense superior al Messiniense superior y quizás en el Plioceno inicial (Fig. 3).

Andrés Galache y Porta (1987) citan de Trigueros (Huelva) Pecten (Amussiopecten) cf. burdigalensis, 


\begin{tabular}{lllll}
\hline Ejemplar & valva & d.a.p. & d.u.p. & ángulo apical \\
\hline MGUS - 2088 & V.D. & 88 & 87 & $129^{\circ}$ \\
MGUS - 2089 & V.I. & 51 & 50 & $122^{\circ}$ \\
MGUS - 2090 & V.D. & 64 & 61 & $127^{\circ}$ \\
MGUS - 2091 & V.I. & - & 107 & $133^{\circ}$ \\
MGUS - 2092 & V.D. & - & 77 & $133^{\circ}$ \\
MGUS - 2093 & V.I. & 92 & 90 & $125^{\circ}$ \\
\hline
\end{tabular}

Tabla 4. Medidas de algunos ejemplares de $F$. expansus. Measurements in some specimens of $\mathrm{F}$. expansus.

durante el Messiniense y de forma no confirmada totalmente, de edad Tabianiense. No ostante, en las búsquedas realizadas en dicha zona, para este trabajo, no se ha comprobado la presencia de esta especie. Sí se ha encontrado la especie $F$. expansus con la que es posible relacionarla.

\section{Observaciones tafonómicas}

Esta especie se encuentra, tanto en Manzanilla como en Bonares, en arcillas arenosas del contacto de la Formación Arcillas de Gibraleón con la suprayacente Formación Arenas de Huelva. Son ejemplares de mediano a pequeño tamaño y les acompaña el pequeño Pecten labnae Mayer.

\section{Distribución}

Esta especie que está bastante difundida a lo largo de todo el Mioceno parece tener su mayor difusión durante el Burdigaliense-Langhiense en todo el Mediterráneo así como por el Atlántico cercano.

Se conoce en el Aquitaniense de Francia, Italia y Hungría; en el Burdigaliense de Francia, Malta, Marruecos, Portugal, Italia y Hungría; en el Langhiense de Francia, Italia, y Libia (Depéret y Roman, 1912; Comaschi Caria, 1972).

En España se cita en el Burdigaliense y Tortoniense de Cataluña (Porta, 1969) y en Trigueros (Huelva) ya comentado anteriormente.

\section{Flabellipecten expansus (Sowerby, 1847)} Fig. 4 E y F

1907 Amussiopecten placenta Fuchs, en Ugolini, 236, lám. 21 , figs. $2,3$.

1912 Flabellipecten expansus (Sowerby); Depéret y Roman, 151, lám. 21, fig. 3; lám. 22, figs.1, 1a.

1914 Pecten (Amussiopecten) expansus Sowerby; Cosman y Peyrot, 292, lám. 15, figs. 3, 5.

1939 Flabellipecten expansus (Sowerby); Roger, 251.

1961 Flabellipecten expansus (Sowerby); Veiga Ferreira, 437, lám. 12, fig. 76.

1971 Flabellipecten expansus (Sowerby); Bauza Rullan, 421.

1972 Flabellipecten expansus (Sowerby); Comaschi Caria, 31, lám. 8, fig. 9.
Material y localidades: El material estudiado procede de Burguillos, Trigueros (MGUS-2092), Alcalá de Guadaira (MGUS-2088, MGUS-2089, MGUS-2090, MGUS-2093), Carmona, Dos Hermanas (MGUS-2091) y Fuentes de Andalucía. Se han estudiado 25 valvas derechas y 17 valvas izquierdas en diferentes estados de conservación. A excepción de algunas valvas izquierdas, los ejemplares que se encuentran completos están adheridos al sedimento e imposibles de separar por la fragilidad de las conchas. De entre ellos se han elegido 6 ejemplares cuyas siglas y medidas figuran en la Tabla 4.

\section{Descripción}

Concha de pared delgada, inequivalva, equilátera, comprimida y algo abierta por los flancos, exteriormente lisa, suborbicular, ligeramente más larga que alta.

Valva derecha poco convexa, umbo poco prominente que no sobrepasa la línea cardinal, la cual es casi recta, muy poco angulosa y sin ninguna escamosidad. El ángulo apical es variable oscilando entre $115^{\circ}$ en los ejemplares jóvenes y $133^{\circ}$ en ejemplares de gran talla. La valva es lisa en el exterior, marcada con algunas líneas concéntricas de crecimiento que se manifiestan más pronunciadas hacia el borde paleal en los ejemplares de mayor tamaño. En algunos ejemplares, observada la valva a contraluz, se aprecian costillas dibujadas, nunca marcadas, en número de 15 a 16. Interiormente, la valva presenta listones muy finos y emparejados, los cuales corresponden a los márgenes de los intervalos. Estas parejas de listones sólo se desarrollan desde el centro de la concha hasta el borde paleal. Los dentelones auriculares son muy prominentes. Orejas medianas y ligeramente desiguales, ornamentadas únicamente por líneas de crecimiento. Los márgenes laterales de dichas orejas son verticales y están redondeados en el vértice superior. La anterior presenta un suave seno bisal.

Valva izquierda planoconvexa, con el margen lateral posterior algo levantado, que da lugar a una débil depresión que va desde el umbo a la periferia. Cara exterior lisa. No obstante, en algunos ejemplares se presentan dibujadas $13 \mathrm{o}$ 14 costillas y en otros, éstas llegan a tener un suave relieve. Como ornamentación secundaria presenta, al igual que la valva derecha, líneas concéntricas de crecimiento, las cuales, en ejemplares de gran tamaño y las cercanas al margen paleal, se manifiestan con unas ondulaciones que corresponden a una insinuación de las costillas. Interiormente presenta listones emparejados en número de 12 a 13 y a cada lado un listón sin pareja. Las orejas son iguales, con línea cardinal recta y los vértices redondeados. Las uniones de éstas con los bordes laterales del disco están separadas por unos canalillos, los cuales hacen que dichos bordes sean unas aristas agudas.

\section{Discusión}

Las especies $F$. expansus y $F$. burdigalensis poseen características muy similares. Existen diferencias, como la falta total de costillas en la cara externa de la valva derecha, en la especie $F$. expansus; y en la cara interna de las valvas, donde los listones forman parejas muy apretadas en $F$. expansus, mientras que en $F$. burdigalensis dichas parejas de listones están más distanciadas. 


\begin{tabular}{lccccc}
\hline Ejemplar & valva & d.a.p. & d.u.p. & $\begin{array}{c}\text { ángulo } \\
\text { apical }\end{array}$ & $\begin{array}{c}\mathrm{n}^{\circ} \\
\text { costillas }\end{array}$ \\
\hline MGUS - 2094 & V.D. & 95 & 84 & $113^{\circ}$ & 21 \\
MGUS - 2095 & V.D. & 98 & 96 & $112^{\circ}$ & 20 \\
MGUS - 2096/a & V.D. & 92 & 81 & $112^{\circ}$ & 22 \\
MGUS - 2096/b & V.I. & 86 & 78 & $123^{\circ}$ & 18 \\
MGUS - 2097 & V.D. & 88 & 79 & $114^{\circ}$ & 21 \\
MGUS - 2098/a & V.D. & 83 & 75 & $110^{\circ}$ & 21 \\
MGUS - 2098/b & V.I. & 78 & 71 & $112^{\circ}$ & 17 \\
MGUS - 2099/a & V.D. & 71 & 64 & $111^{\circ}$ & 21 \\
MGUS - 2099/b & V.I. & 67 & 62 & $118^{\circ}$ & 17 \\
MGUS - 2100 & V.D. & 82 & 74 & $113^{\circ}$ & 22 \\
\hline
\end{tabular}

Tabla 5. Medidas de algunos ejemplares de F. bosniasckii. Measurements in some specimens of $\mathrm{F}$. bosniasckii.

Los ejemplares estudiados se encuentran en todas las fases de crecimiento. Son más frecuentes los de mediano tamaño, salvo dos ejemplares recolectados en Dos Hermanas (Fig. 4E), cuyos tamaños se acercan a los descritos de Portugal e Italia por Depéret y Roman (1912) y Ugolini (1907), respectivamente (Tabla 4).

La especie, hasta ahora, se ha citado en el Mioceno inferior y medio. En la zona aquí estudiada se ha localizado desde el Tortoniense superior al Messiniense superior y quizás Plioceno inferior de Trigueros (Fig. 3).

\section{Observaciones tafonómicas}

Ante la presencia frecuente de esta especie, considerada del Mioceno inferior y medio, en las calcarenitas de la Formación Guadaira, cuya edad es Messiniense, se han estudiado los ejemplares para comprobar la posibilidad de que estuvieran resedimentados y/o reelaborados. Su abundancia, dispersión, presencia de ejemplares articulados cuyo sedimento interno y externo es el mismo, y el buen estado de conservación de los ejemplares, a pesar de la fragilidad de sus valvas, confirman que se trata de organismos no retrabajados de sedimentos más antiguos. Por otro lado, ninguna valva aparece colonizada en su interior por organismos incrustantes, aunque algunas sí lo están en su cara externa (briozoos, serpúlidos).

La falta de colonización y la conservación intacta de ejemplares frágiles permiten suponer que estos organismos, una vez muertos, no permanecieron expuestos sobre el sustrato durante mucho tiempo, y que apenas sufrieron transporte. Por tanto, se puede establecer que vivieron y murieron en el mismo lugar, o muy próximo a éste, donde posteriormente fosilizaron.

Se puede concluir, por tanto, que esta especie estaba adaptada a las condiciones en las que se depositaron las calcarenitas donde vivían, es decir, ambiente somero de plataforma carbonatada abierta, arenoso, con abundantes bioclastos, aguas agitadas, temperatura media $15-18^{\circ} \mathrm{C}$ y salinidad normal (Clauss Klamp, 1991).

\section{Distribución}

El material tipo proviene del Burdigaliense de Porto Brandao, en las cercanías de Lisboa (Portugal), de donde lo citan Deperet y Roman (1912) y Veiga Ferreira (1961).

También se cita en el Burdigaliense de Burdeos y Cesta, en Francia, en Irán, Malta, Italia y en Egipto (cerca de El Cairo). En este último lugar fue citada por Fusch como Pecten genefensis (Depéret y Roman, 1912).

Comaschi Caria (1972) lo cita en el Langhiense de Aquitania (Francia), Cagliari (Italia), Egipto, Irán y Mallorca (España).

En España únicamente ha sido identificado, hasta ahora, en el Mioceno medio de Mallorca (Bauza Rullan, 1971).

\section{Flabellipecten bosniasckii (De Stefani y Pantanelli, 1880) \\ Fig. $4 \mathrm{C}$}

1897 Pecten bosniasckii Stefani y Pantanelli, en Sacco, 56, lám. 17, figs. 1-5.

1910 Flabellipecten bosniasckii (De Stefani y Pantanelli); Depéret y Roman, 107-109, lám. 12, figs. 1,1a .

1939 Flabellipecten bosniasckii (De Stefani y Pantanelli); Roger, 247.

1971 Flabellipecten bosniasckii (De Stefani y Pantanelli); Méndez Cecilia, 488, lám. 1, figs. 3, 6 y 7.

1971 Flabellipecten bosniasckii (De Stefani y Pantanell); Demarcq, en Brebion et al., 204.

1990 Flabellipecten bosniasckii (De Stefani y Pantanelli); Demarcq, 45, 48.

1996 Flabellipecten bosniasckii (De Stefani y Pantanelli); Aguirre et al., 291-308, lám. 1, fig. 4.

Material y localidades: El material estudiado procede de El Rompido (Cartaya) (MGUS- 2096/a, hasta MGUS- 2100), Jerez de la Frontera, Nueva Jarilla (Jerez de la Fr.) y Mesas de Asta ( MGUS- 2094, MGUS- 2095). Han sido estudiadas 100 valvas derechas y 60 valvas izquierdas además de numerosos fragmentos. El estado de conservación es diverso desde algunos con fuerte proceso de disolución a otros muy bien conservados, completos y articulados. De estos últimos, se han elegido 10 cuyas siglas y medidas quedan reflejadas en la Tabla 5 .

\section{Descripción}

Concha de mediano tamaño, inequivalva y equilateral en cuanto a la forma, no en cuanto a su ornamentación pues sus costillas son de desigual anchura.

Valva derecha suavemente convexa, con el umbo poco prominente que no rebasa el borde cardinal. El ángulo apical varía entre $110^{\circ}$ y $115^{\circ}$. El número de costillas es de 18 a 23 , desiguales en anchura, bien definidas y que no se atenúan hacia el borde paleal. Se observan algunas costillas de casi doble anchura que las normales y, con frecuencia, estas costillas anchas presentan un surco longitudinal que las divide en dos costillas más estrechas y apretadas que las demás. La silueta de las costillas es subcuadrangular, con las aristas redondeadas. Los intervalos son siempre más estrechos que las costillas. Como ornamentación secundaria 
presenta abundantes líneas concéntricas de crecimiento, que no forman lamelas. Orejas grandes, la posterior se corta perpendicular al borde cardinal, la anterior, algo más curvada, presenta lineas radiales y un suave seno bisal en la base.

Valva izquierda plana, a veces muy suavemente convexa. Provista de 18 a 20 costillas bien resaltadas, de perfil subcuadrangular y más estrechas que los intervalos. A veces presenta costulaciones más débiles, incluso una suave línea intercalada entre las costillas principales. Los intervalos presentan lamelas de crecimiento muy apretadas que en ocasiones también se hacen patentes sobre las costillas. Orejas subiguales, cortadas casi verticalmente respecto a la línea cardinal y redondeadas en el vértice superior, ornamentadas por algunas líneas de crecimiento y en algunos ejemplares se aprecian líneas radiales.

\section{Discusión}

Los ejemplares de los géneros Pecten y Flabellipecten, que son frecuentes entre los abundantes pectínidos de los materiales del Plioceno inferior de El Rompido (Fig. 3), tienen como caracteristicas comunes sus valvas izquierdas planas o mínimamente convexas, además de la frecuente desigualdad en el ancho de sus costillas por división de algunas anchas en dos costillas más estrechas. Estos caracteres comunes hacen, a veces, dificil su determinación. Por estas mismas caracteristicas, una vez identificados como Flabellipecten, se les reconoce su pertenencia al grupo bosniaskii, grupo que se considera de conexión entre ambos géneros.

En el citado yacimiento de El Rompido, aparecen ejemplares con 24 y 25 costillas y éstas son más regulares en su anchura. Estos ejemplares se han clasificados como $F$. flabelliformis.

Comaschi Caria (1972) considera F. bosniasckii sinónima de $F$. flabelliformis. En este trabajo se ha optado por mantener ambas especies separadas en espera de que se realice una revisión exaustiva de ambas especies.

El tamaño de los ejemplares estudiados se encuentran dentro de los límites normales que establecen Depéret y Roman (1910). Según estos autores, las medidas varían entre 60 y $80 \mathrm{~mm}$, excepcionalmente llegan a $100 \mathrm{~mm}$.

\section{Observaciones tafonómicas}

En El Rompido, esta especie es frecuente en arenas limosas marrones rojizas. Menos frecuentemente se encuentra en el tramo inferior de arenas margosas beiges, donde la acompaña una abundante malacofauna de entre la que interesa resaltar la subespecie Palliolum (Lissochlamys) excisum perstriatula Sacco, pectínido escasamente citado en todo el mundo y que también aparece de forma abundante junto a $F$. bosniasckii en materiales arenosos del Plioceno en Mesas de Asta y Jerez de la Frontera.

\section{Distribución}

Esta especie es muy conocida en el Plioceno de la zona mediterránea. Es citada en abundantes yacimientos italianos (Toscana, Piamonte, Liguria, Bordighera, Masserano,
Savone, Zinola, Albenga, Vintimille, Ventimiglia, Piacentino, Siena, Palermo, etc.). En Francia, se cita en Saint-Romain. En Argelia, en Medjana y Hadjout (Depéret y Roman, 1910; Roger, 1939).

Roger,(1939), cita esta especie en el Mioceno de Cerdeña ( arenas de Barabo).

En España ha sido citada en Almería, Cuesta de los Alacranes, la subespecie $F$. bosniasckii acosticillata (Méndez Cecilia, 1971) y en la cuenca de Almería-Nijar (Aguirre et al.,1996). Roger (1939) la cita en Parazuelos, cerca de Cartagena. También en Elche, Sierra Colmenar, se cita la subespecie $F$. bosniasckii acosticillata (Demarcq, en Brebion et al., 1971). Este mismo autor (Demarcq, 1990, pág. 46), la cita en el Messiniense del Neógeno Bético, sin precisar localidad. No obstante, es posible que también la estudiara en El Rompido (Huelva), ya que hace mención a este yacimiento para una especie muy cercana, $F$. nigromagnus Sacco.

\section{Flabellipecten flabelliformis (Brocchi, 1814)}

1814 Ostraea flabelliformis Brocchi, 580.

1897 Flabellipecten flabelliformis (Brocchi); Sacco, 55, lám. 15, figs. 1-4.

1908 Pecten nicolai Ugolini, 203, lám. 24, fig. 9.

1912 Flabellipecten flabelliformis (Brocchi); Déperet y Roman,139, lám. 18, figs.1, 1a, 2.

1939 Flabellipecten flabelliformis (Brocchi); Roger, 250.

1971 Flabellipecten flabelliformis (Brocchi); Demarcq en Brebion et al., 204.

1971 Flabellipecten flabelliformis (Brocchi); Méndez Cecilia, 487, lám. 1, fig. 4.

1972 Flabellipecten flabelliformis (Brocchi); Comaschi Caria, 29, lám. 6, fig. 7.

1987 Flabellipecten flabelliformis (Brocchi); Andrés Galache y Porta, lám. 2, fig. 4.

1990 Flabellipecten flabelliformis (Brocchi); Demarcq, 46.

Material y localidad : El material estudiado procede de El Rompido (Cartaya), han sido 8 valvas derechas y 3 valvas izquierdas deterioradas salvo 2 valvas derechas casi completas, de las cuales se han tomado las medidas que se representan en la Tabla 6 .

\section{Descripción}

Concha de mediano tamaño, inequivalva, equilateral y comprimida, ligeramente más larga que alta.

Valva derecha convexa, poco profunda, umbo poco prominente que no rebasa el borde cardinal. Su ángulo apical varía entre $110^{\circ}$ y $120^{\circ}$. La ornamentación principal de la valva está formada por 24 o 25 costillas que, aun presentando un aspecto muy regular, no son totalmente iguales en cuanto a su anchura. Una o dos costillas a ambos márgenes son más débiles que las restantes y, a veces, algunas centrales también difieren en anchura.

Perfil de las costillas subcuadrangular con las aristas redondeadas. Intervalos planos y muy estrechos. La superficie de la valva presenta líneas de crecimiento concéntricas y apretadas, con mayor resalte en el borde 


\begin{tabular}{lccccc}
\hline Ejemplar & valva & d.a.p. & d.u.p. & $\begin{array}{c}\text { ángulo } \\
\text { apical }\end{array}$ & $\begin{array}{c}\mathrm{n}^{\circ} \\
\text { costillas }\end{array}$ \\
\hline MGUS - 2101 & V.D. & 74 & 64 & $114^{\circ}$ & 25 \\
MGUS - 2102 & V.D. & 81 & 72 & $116^{\circ}$ & 24 \\
\hline
\end{tabular}

Tabla 6. Medidas de algunos ejemplares de $F$. flabelliformis. Measurements in some specimens of $\mathrm{F}$. flabelliformis.

paleal. Orejas grandes, la posterior cortada perpendicularmente respecto a la línea cardinal, mientras que la anterior tiene un límite sinuoso con un marcado seno bisal en la base. Ambas orejas marcadas con líneas de crecimiento. La anterior presenta unos listones radiales de los cuales el más marcado corresponde al comienzo del seno bisal.

Valva izquierda plana. Los márgenes, ornamentados por una serie de finas y apretadas estrías radiales, se elevan poco sobre el plano de la concha. Provista de un número variable de costillas, 19 a 21, siempre más estrechas que los intervalos, subredondeadas y bien marcadas. La valva está cubierta de finas y apretadas lamelas de crecimiento visibles sobre todo en los intervalos. Orejas grandes que se cortan casi perpendiculares a la línea cardinal, que es recta.

\section{Discusión}

El material estudiado de esta especie ha sido escaso. El número de costillas varía entre 24 y 25 . Comascchi Caria (1972) admite para esta especie de 21 a 25 costillas al unificar $F$. bosniasckii y $F$. flabelliformis.

Los ejemplares estudiados son de tamaño mediano y pequeño respecto de la medida orientativa dada por Depéret y Roman (1912), que es de 118 mm de d.a.p. (Tabla 6).

\section{Distribución}

La especie se extiende desde el Mioceno superior hasta el Plioceno superior por toda la zona mediterránea y por yacimientos atlanticos de la Cuenca del Guadalquivir.

En Italia se cita en el Mioceno de Toscana, Piamonte y Calabria. Para el Plioceno, las citas, en su mayoría, son las mismas que para $F$. bosniasckii. Es frecuente en el Piamonte, Liguria, Palermo, Sicilia y Piacentino donde Sacco (1897) la cita como muy abundante. En Francia, zona de Niza; en Tunez, Monastir; en Argelia, Cinq-Palmier y Tadjena (Orán); en Grecia, Moreé (Depéret y Roman, 1912; Comaschi Caria,1972).

En España, se cita en Santa Pola y Sierra de la Marina, en la provincia de Alicante (Demarcq, en Brebion et al., 1971) y en Cuesta de los Alacranes, Almería (Méndez Cecilia, 1971). Andrés Galache y Porta (1987) citan esta especie (tabla I, pág. 146) y la figuran (lám. II, fig. 4).

\section{CONCLUSIONES}

En los materiales neógenos de Andalucía occidental se ha comprobado la presencia de las siguientes especies del género Flabellipecten: $F$. solarium, $F$. fraterculus, $F$. burdigalensis, $F$. expansus, $F$. bosniasckii y $F$. flabelliformis.

Respecto de las especies $F$. burdigalensis y $F$. expansus que, hasta ahora, han sido consideradas como propias del Mioceno inferior y medio, se ha comprobado su existencia durante el Mioceno superior e incluso pudieran haberlo sobrepasado (Fig. 2).

Por otro lado, se han podido deducir ciertas condiciones del hábitat de la especie $F$. expansus: ambiente somero de plataforma abierta, aguas agitadas, temperatura media de $15-18^{\circ} \mathrm{C}$ y salinidad normal.

Para la especie $F$. bosniasckii se ha de considerar, en su descripción, una mayor variabilidad en el número de costillas, 18 a 22 en vez de 18 a 20 admitidas por otros autores (De Stefani y Pantanelli, 1880; Depéret y Roman, 1910).

\section{AGRADECIMIENTOS}

Al Dr. Eduardo Mayoral por haber realizado la primera lectura y corrección del manuscrito aportando valiosos comentarios. Al Dr. Gerard Demarcq por sus opiniones en la clasificación y cronología de algunas especies. A D. Ildefonso Bajo y D. Francisco González Portillo por sus ayudas en las fotografías, así como a los Dres. González Delgado, Julio Aguirre y $\mathrm{M}^{\mathrm{a}}$ Luisa Martínez Chacón que en sus correcciones sugirieron dar un enfoque diferente al trabajo con el cual ha mejorado sustancialmente.

\section{BIBLIOGRAFÍA}

Acuña, J.D. 1978. Malacología del Mioceno marino de la provincia de Valencia. Estudios Geológicos, 34, 281291.

Aguirre, J., Braga, J.C., Jiménez, A.P. and Rivas, P. 1996. Substrate-related changes in pectinid fossil assemblages. Palaeogeography, Palaeoclimatology, Palaeoecology, 126, 291-308.

Andrés Galache, I. y Porta, J. 1987. La distribución de los pectínidos en el Neógeno de Huelva. Datos preliminares. In: Paleontología del Neógeno de Huelva (W. Cuenca del Guadalquivir). Ediciones Universidad de Salamanca, 143-151.

Baceta, J.I. y Pendón, J.G. 1999. Estratigrafía y arquitectura de facies de la Formación Niebla, Neógeno superior, sector occidental de la Cuenca del Guadalquivir. Revista de la Sociedad Geológica de España, 12, 419-438.

Bauza Rullan, J. 1971. Paleontología de Mallorca.- Ciento ochenta millones de años de la flora y fauna de Mallorca. In: Historia de Mallorca. Palma de Mallorca, 421.

Ben Moussa, A., 1994. Les bivalves Néogènes du Maroc septentrional (façades Atlantique et Méditerranéenne). Biostratigraphie, paléobiogéographie et paléoécologie. Document Laboratoire Géologique, Lyon, 132, 281 pp.

Ben Moussa, A., Demarcq, G. et Lauriat-Rage, A. 1987. Pectinides Messiniens du Bassin de Melilla (NE Maroc). Comparaisons inter-regionales et interes paleobiologiques. Revue de paléobiologie, 6, 111-129. 
Brebion, Ph., Demarcq, G., Lauriat, A. et Montenat, Ch. 1971. Le pliocène de la région d'Elche (province d'Alicante, Espagne) et sa faune de mollusques. Estudios Geològicos, 27, 197-211.

Brocchi, G. 1814. Conchiologia fossile subappennina con osservazioni geologiche sugli Appennina e sul soulo adiacente. Stamperia reale, 2, 241-712.

Cárdenas, J. 1998. Nuevas localidades para Amussiopecten (C.) koheni. Batalleria, 8, 23-28.

Civis, J., Sierro, F.J., González-Delgado, J.A., Flores, J.A., Andrés, I., Porta. J. y Valle, M.F. 1987. El Neógeno marino de la provincia de Huelva: Antecedente y definición de sus unidades litoestratigráficas. In: Paleontología del Neógeno de Huelva. Ediciones de la Universidad de Salamanca, 9-21.

Clauss Klamp, F.L. 1991. Las microfacies carbonatadas neógenas en un sector occidental de la depresión del Bajo Guadalquivir. Estudios Geológicos, 47, 183-192.

Comaschi Caria, I. 1972. I pectinidi del Miocene della Sardegna. Stabilimento Tipografico Editoriale Fossataro. Cagliari, 5- 82.

Cossman, M. et Peirot, A. 1914. Conchologie néogenique de l'Aquitaine. Pélécypodes. Acta société linnéenne de Bordeaux, 68, 411-496.

Crespo, A., Martínez Díaz, C., Martínez-Fresneda, F., Granados-Granados, L., Pan Arana, T., Leyva, F., Ferández-Luanco, M.C. 1977. Mapa Geológico de España, escala 1:50.000. Explicación de la Hoja $n^{\circ} 986$, Fuentes de Andalucía. Instituto Geológico y Minero de España, 1-20.

Csepreghy-Meznerics, I. 1960. Pectinidés du Néogène de la Hongrie et leur importance biostratigraphique. Mémoire de la Société Géologique de France (Nouvelle série), 92 , 5-56.

Darder, B. 1945. Estudio geológico del sur de la provincia de Valencia y del norte de Alicante. Boletín del Instituto Geológico y Minero de España, 57, 369-837.

Demarcq, G. 1979. Essai de synthese biostratigraphique sur les Pectinidés du Néogène Méditerranéen. Annales Géologique Pays Hellen, 1, 305-307.

Demarcq, G. 1990. Les faunes de pectinidés du Néogène bétique. Documents et Travaux IGAL, 12-13, 45-48.

Depéret, Ch. et Roman, F. 1910-1912. Monographie des Pectinidés néogènes de l'Europe et des régions voisines. II. Flabellipecten. Mémoire de la Société Géologique de France. Paléontologie, 26, 105-169.

De Stefani, C. e Pantanelli, C. 1880. Molluschi pliocini dei dintorni di Siena. Bollettino della Società Malacologica Italiana, 4, 5-215.

Freneix, S., Saint Martin, J.P. et Moissette, P. 1987. Bivalves ptériomorphes du Messinien d Oraine (Algérie occidentale). Bulletin Muséum national d'Historie naturelle. Paris, (4 ${ }^{\mathrm{a}}$ sèrie), 9, 3-61.

Gliber, M. et Van de Poel, L. 1965. Les bivalvias fossiles du Cénozoïque étranger des collections de l'Institut Royal des Sciences Naturelles de Belgique. Pteroconchida, Colloconchida et Isofilibranchida. Mémoires Institut Royal des Sciences Naturelles de Belgique, 78, 1-105.
Lamarck, J.B. 1806. Suite des Mémoires sur les fossiles des environs de Paris. Annales du Muséum d'Historie naturelle, Paris, 8, $355 \mathrm{pp}$.

Lamarck, J.B. 1819. Histoire Naturelle des Animaux sans vertèbre. Paris, vol. 6, 343 pp.

Martínez del Olmo, W., García Mallo, J., Leret Verdu, G., Serrano Oñate, A. y Suárez Alba, J. 1984. Modelo tectosedimentario del Bajo Guadalquivir. I Congreso Español de Geología, 1, 199-213.

Méndez Cecilia, M.A. 1971. Pectínidos pliocenos de Almería. Estudios Geológicos, 27, 487-495.

Perconig, E. y Granados, L.F. 1973. La caliza tosca de Arcos de la Frontera. In: III Coloquio Europeo de Micropaleontología. Empresa Nacional Adaro de Investigaciones Mineras Sociedad Anónima (E.N.A.D.I.M.S.A.), Madrid, 293-300.

Porta, J. de, 1969. Catálogo sistemático y estratigráfico de los pectínidos del Neógeno al N.E. de España (excepto Baleares). Acta Geológica Hispánica, 4, 135-142.

Portero García, J.M. y Álvaro López, M. 1984. La depresión del Guadalquivir, cuenca de antepaís durante el Neógeno: Génesis, evolución y relleno final. I Congreso Español de Geología, 3, 241-252.

Roger, J. 1939. Le genre Chlamys dans les formations néogènes de l'Europe. Mémoire Société géologie de France, 40, 294 pp.

Ruiz Reig, P., García de Domingo, A., Hernaiz, P., González, J., Cabra, P., Balanya, J.C., García Dueñas, V., García Ramos, J.C.M., Aguilar, P., Young, J.R. 1994. Mapa Geológico de España, escala 1: 200.000. Explicación de la hoja $n^{\circ}$ 86, Cádiz. Instituto Tecnológico Geominero de España, 1-46.

Sacco, F. 1897. I molluschi dei terreni terziarii del Piamonte e della Liguria. Parte 24. Carlo Clausen, Turín, 66 pp.

Serra, G. 1941. Su due nuove specie di Pettinidi del Neogene italiano. Bollettino della Società Geologica Italiana, 40, 82-88.

Sierro, F.J., González-Delgado, J.A., Flores, J.A., Dabrio, C., and Civis, J. 1990. The Neogene of the Guadalquivir Basin (SW Spain). Paleontologia i Evolució, Memória Especial 2, 209-250.

Sierro, F.J., González-Delgado, J.A., Dabrio, C., Flores, J.A. and Civis, J. 1996. Late Neogene depositional sequence in the foreland basin of Guadalquivir (SW Spain). In: Tertiary basins of Spain (Eds. P.F. Friend and C. Dabrio). Cambridge University Press, 339-345.

Sowerby, G.B. 1841. In Smith, 1847: On the age of the Tertiary beds of the Tagus with a catalogue of the fossiles. Quaterly Journal of Geological Society of London, 3, 419 pp.

Sowerby, G.B. 1847. Thesaurus Conchyliorum: Monography of the Genus Pecten. 1, 45-82.

Ugolini, R. 1907-1908. Monografia dei Pettinidi neogenici della Sardegna. Generi Amussiopecten (cont.), Flabellipecten, Pecten. Paleontographia Italica, 14, 191224.

Veiga Ferreira, O. 1951. Os Pectinideos do Miocénico do Algarve. Comunicaçoes dos Serviços Geológico de Portugal, 32, 5-27.

Veiga Ferreira, O. 1954. Pectinídeos do Miocénico do Vale 
do Sado e da Serra da Arrábida. Comunicaçoes dos Serviços Geológico de Portugal, 35, 5-35.

Veiga Ferreira, O. 1961. Pectinídeos do Miocénico da Bacia do Tejo. Comunicaçoes dos Serviços Geológico de Portugal, 45, 419- 465.

Verdenius, J.G. 1970. Neogene stratigraphy of the western
Guadalquivir Basin (Southern Spain). Utrecht Micropaleontology Bulletin, 3, 1-103.

Viguier, C. 1974. Le Néogene de l'Andalousie Nord occidentale (Espagne). Histoire géologique du "Bassin du Bas-Guadalquivir. Thése Doctoral, Université de Burdeaux, 450 pp.

Manuscrito recibido: 15 de marzo, 2002 Manuscrito aceptado: 3 de enero, 2003 